
Motrivivência
v. 28,
n. 47 ,
p. 31-46, maio/2016

\title{
UMA INTERPRETAÇÃO DOS CUIDADOS CORPORAIS A PARTIR DOS USUÁRIOS DE UM PROGRAMA DA REDE PÚBLICA DE SAÚDE NA CIDADE DE VITÓRIA/ES
}

\author{
Thacia Varnier \\ Felipe Quintão Almeida² \\ Ivan Gomes ${ }^{3}$
}

\section{RESUMO}

Este artigo trata de temáticas relacionadas com a Educação em Saúde e o comportamento de risco. Teve como objetivo investigar como os usuários lidam com as informações que recebem de um programa de Educação em Saúde, oferecido nas Unidades Básicas de Saúde da cidade de Vitória no Estado do Espírito Santo/Brasil, voltado para a intervenção de indivíduos com sobrepeso e obesos. Os instrumentos metodológicos utilizados foram observação participante, entrevistas semiestruturadas e a experimentação da técnica Narrativas de Mapas Corporais. Após as análises, conclui que os indivíduos apresentaram comportamentos de conformidade ao absorverem e transportarem as condutas orientadas pelos especialistas para o seu cotidiano. Tal constatação pode estar atrelada ao fato de que, na sociedade contemporânea, o modelo de viver bem é o estilo de vida saudável, no qual a "naturalização" desses ideais acaba por contribuir na aceitação dessas normas ao acreditarem que essa seria a única forma correta de vida.

Palavras-chave: Obesidade; Educação em Saúde; Estilo de Vida Saudável

1 Mestre em Educação Física. UFES, Vitória/Espírito Santo, Brasil. E-mail: thacia_151@hotmail.com

2 Doutor em Educação. Professor do Departamento de Educação Física da UFËS. Vitória/Espírito Santo, Brasil. E-mail: fqalmeida@hotmail.com

3 Doutor em Ciências Humanas. Professor do Departamento de Educação Física da UFES. Vitória/Espírito Santo, Brasil. E-mail: ivanmgomes@hotmail.com 


\section{INTRODUÇÃO}

Este artigo é parte de uma pesquisa que se apropria das perspectivas das ciências humanas e sociais para analisar os preceitos de vida saudável/ativa na educação dos corpos e na regulação da saúde. ${ }^{3}$ A sua discussão está ancorada nas temáticas relacionadas com as estratégias educativas em saúde e comportamento de risco, cujo interesse foi concretizado por meio da investigação de um programa de Educação em Saúde voltado para indivíduos com excesso de peso.

Segundo Pimont (1997) e Morosini, Fonseca e Pereira (2009), a Educação em Saúde está articulada aos objetivos gerais da Saúde Pública, como prevenção de doenças, proteção e promoção da saúde do indivíduo, da família e da comunidade, a qual se apropria de recursos para intervir na sociedade mediante a atuação individual e coletiva dos sujeitos. Salientamos que a discussão de Educação em Saúde vai muito além de uma definição conceitual, por compreendermos que o conceito emerge de processos e mudanças sócio-históricos erigidas no âmbito da saúde, a qual adquiriu significados diferentes de acordo com a área de aplicação. Para Schall e Strunchiner (1999),

A Educação em Saúde é um campo multifacetado, para o qual convergem diversas concepções, das áreas tanto da educação, quanto da saúde, as quais espelham diferentes compreensões do mundo, demarcadas por distintas posições político-filosóficas sobre o homem e a sociedade (SCHALL; STRUCHINER, 1999, p. 1).

Em relação aos programas de Educação em Saúde que se apropriam de concepções relacionadas à promoção de saúde e prevenção de doenças ${ }^{4}$, geralmente, o foco das suas ações educativas está voltado à promoção de um estilo de vida saudável/ ativo e ao combate à obesidade, ao sobrepeso e ao sedentarismo (FRAGA, 2006; BAGRICHEVSKY et al., 2007; GOMES, 2009; RAMIRO, 2008). Dentre os programas relacionados com a temática, destacamos um programa oferecido nas Unidades Básicas de Saúde (U.B.S.) da cidade de Vitória/ES. ${ }^{5}$ Nesse sentido, o objetivo, neste estudo, foi investigar como os participantes lidam com as informações que recebem do programa. A seguir, veremos detalhes sobre o programa, como uma estratégia de Educação em Saúde.

\section{O programa como uma estratégia de Edu- cação em Saúde}

O programa teve início no ano de 2006 e possui uma proposta direcionada ao combate da obesidade no campo da Saúde Pública na cidade de Vitória. De acordo com os documentos do projeto acessados, ${ }^{6}$

3 A investigação contou financiamento na modalidade de bolsa de mestrado (CAPES).

4 Promoção da saúde compreende o processo de capacitação da comunidade para que ela própria possa exercer ações para a melhoria da sua qualidade de vida e saúde informada pelo conhecimento científico dos riscos à saúde. Esse processo enfatiza a autonomia dos sujeitos e grupos sociais na gestão da saúde e na busca coletiva por direitos sociais (CZERESNIA, 2004). Já quanto à prevenção de doenças, o enfoque se restringe à doença (BUSS, 2009).

5 Para preservação da ética da pesquisa, omitimos a identidade do programa. O projeto desta pesquisa foi enviado ao Comitê de Ética e aprovado sob o nº 13016813.3.0000.5542.

6 Fontes não publicadas. 
o programa incentiva à prática de atividades físicas, a adesão de uma alimentação saudável e o controle psicológico, objetivando a redução de peso e a mudanças de hábitos de vida dos usuários. Por meio de palestras e dinâmicas de grupo, o programa tem o propósito de informar, orientar e educar os participantes sobre os cuidados, agravos e riscos que todas as pessoas possuem em relação à saúde, buscando a prevenção e promoção da saúde, em especial, nos aspectos relacionados com a obesidade. Além disso, tem como premissa o acompanhamento de seus usuários por uma equipe multiprofissional composta por: professores de Educação Física, médicos, psicólogos, assistentes sociais, nutricionistas, enfermeiros e agentes comunitários de saúde. Em relação à organização das atividades do programa, são ofertados para a comunidade módulos a serem discutidos em dez encontros. A cada semana um encontro é realizado, sempre no mesmo horário e dia. Encerrado esse módulo com dez encontros, os agentes de saúde distribuem novamente os convites do programa para a comunidade e, assim, um novo módulo com dez encontros é oferecido novamente. O programa está presente em sete Unidades Básicas de Saúde de Vitória/ES e, em nove anos de existência, mais de 135 pessoas participaram do projeto.

Segundo relato da professora de Educação Física do programa, o perfil dos participantes do projeto é de indivíduos de ambos os sexos, com idade acima de 18 anos, moradores do território atendido pela U.B.S. e que apresentam IMC acima de $30 \mathrm{~kg} / \mathrm{m}$ ou sobrepeso com comorbidades. ${ }^{7}$

\section{METODOLOGIA}

Para a construção desta pesquisa, acompanhamos três módulos (30 encontros) oferecidos pelo programa em uma Unidade de Saúde. ${ }^{8}$ No que se refere aos aspectos metodológicos, utilizamos os instrumentos da observação participante e de entrevistas semiestruturadas (MACEDO, 2000), além do experimento inspirado no método das Narrativas de Mapas Corporais (GASTALDO et al., 2012). Ressaltamos que essa técnica metodológica não foi o nosso método principal, mas nos serviu de apoio para enriquecer as nossas análises. Em linhas gerais, o método Narrativas de Mapas Corporais foi proposto por Gastaldo et al. (2012) e contém três elementos fundamentais: o testemunho, que é uma breve narrativa sobre quem é o participante e suas circustâncias (essa história é contada ao final da última sessão, quando o participante visualiza o mapa completo, pronto); o mapa corporal ( $2 \mathrm{~m}$ de comprimento), que não pode ser interpretado sem uma chave de leitura; e a chave de leitura do mapa, que descreve cada elemento do mapa na primeira pessoa. ${ }^{0}$ O corpo de análise desta pesquisa foi composto por oito usuários ${ }^{9}$ que

7 "O termo comorbidade é formado pelo prefixo latino 'cum', que significa [...] correlação, companhia, e pela palavra morbidade, originada de 'morbus', que designa estado patológico ou doença. Assim, deve ser utilizado apenas para descrever a coexistência de transtornos ou doenças e não de sintomas" (PETRIBÚ, 2001, p. 1).

8 A participação na pesquisa foi voluntária e aqueles que concordaram assinaram o Termo de Consentimento Livre e Esclarecido.

9 Vale ressaltar que preservamos as identidades dos participantes nesta pesquisa ao adotarmos nomes fictícios nas narrativas apresentadas. 
acompanharam regularmente os encontros do programa ofertado em uma U.B.S. no ano de 2013, além da psicóloga e da professora de Educação Física dessa Unidade de Saúde. O perfil do grupo de usuários apresentou um usuário do sexo masculino e sete usuárias do sexo feminino, com faixas etárias entre 33 e 70 anos de idade $(33,36$, $47,52,60,61,63$ e 70 anos). Os integrantes apresentam IMC variado entre sobrepeso e obesidade mórbida. Assim, o grupo contém: um participante com sobrepeso (IMC: 29,8), cinco com obesidade (IMCs: 31,$62 ; 33,96$; $37,46 ; 38,33$ e 32,4$)$ e dois participantes com obesidade mórbida (IMC: 44, 38 e $44,60)$.

Para melhor compreensão dos argumentos desenvolvidos nesta pesquisa, organizamos o texto em dois tópicos. No primeiro, intitulado "Em busca da segurança: o programa como conselheiro", procuramos investigar os interesses que levaram os usuários a buscar o programa. No segundo, denominado "Entre ações e discursos: a recepção dos usuários em frente aos discursos dos especialistas do programa", interpretamos como os participantes lidam com as informações recebidas pelos especialistas, bem como o que fazem com elas. E, por fim, apresentamos as considerações finais deste estudo.

\section{Em busca da segurança: o programa como conselheiro}

Segundo Bauman (2011), a constituição da sociedade contemporânea implicou mudanças no pensar e agir socialmente. Nessa nova forma de produção das subjetivações, os sujeitos vivem um processo de individualização no qual se tornam responsáveis por suas escolhas e pela construção reflexiva de suas biografias. A responsabilidade é direcionada no sujeito vinculando-se na lógica da proteção ao corpo, território a ser protegido. Esse diagnóstico é reforçado por Czeresnia (2004, p. 442):

[...] O refinamento dos costumes vinculou-se ao desenvolvimento de lógicas e técnicas de proteção do corpo. As fronteiras corporais tenderam a tornar-se progressivamente mais demarcadas e os corpos mais defendidos.

O processo de individualização e privatização do espaço público é um fenômeno que contribui para que o indivíduo contemporâneo se torne o construtor do seu próprio destino, do seu corpo e de sua identidade. A ele é dada a "liberdade" de fazer escolhas, transportando para si a responsabilidade pelas suas ações. Nesse sentido, cabe ao indivíduo buscar, por meio do seu próprio esforço, soluções para problemas de ordem privada (BAUMAN, 2001). Dentro desse cenário, o contexto moderno líquido exigiu um novo cuidado dos corpos. O corpo contemporâneo é um corpo flexível, "apto" e ágil para enfrentar a vida acelerada e os prazeres proporcionados pelo consumo. Ele é o receptor de sensações, capaz de absorver as diferentes experiências emergidas do mundo. Seu destino possui como finalidade uma vida longa e saudável, cuja aparência estética se torna passível de ser comprada e construída. Portanto, o corpo não é somente o lócus do desejo, mas também se configura como o alvo do próprio desejo (BAUMAN, 2010).

Uma outra faceta desse processo ocorre na busca pela diminuição das incertezas e angústias humanas. Nessa direção, o 
racionalismo moderno se edifica como um saber legitimado pelas instituições sociais, do qual se torna instrumento de administração e controle da vida. Para Czeresnia (2004), por meio da racionalidade científica, o indivíduo foi capaz de ampliar o poder de controlar as ações e escolhas da vida, podendo decidir ativa e "livremente" as escolhas informadas para a diminuição dos riscos. Nesse sentido, o risco se torna um importante instrumento para a "arbitragem social", e distintos setores políticos, econômicos e sociais se apropriaram desse dispositivo para a orientação dos indivíduos nas escolhas consideradas "corretas" (MITJAVILA, 2002). Em uma sociedade em que o corpo se torna o principal lócus de afirmação de identidade, ao indivíduo é disponibilizada uma infinidade de opções para serem seguidas e consumidas em busca de "solucionar" os problemas e alcançar o corpo almejado, sarado. Tal aspecto foi identificado entre os usuários entrevistados ao indicarem a necessidade de acessar essas recomendações no programa.

As estratégias de defesa do corpo difundem-se subjetivamente na ânsia da diminuição das angústias e incertezas emergidas na atualidade na tentativa de transformar o corpo em um território seguro. Segundo Gomes (2009), esse panorama propiciou a multiplicação de dispositivos com propostas e ferramentas para auxiliar os indivíduos na promoção do corpo saudável. São conselheiros que possuem a incumbência de orientar as pessoas para a "vida saudável". Ocorre então um processo de regulação em que os sujeitos são impelidos a realizar livremente escolhas saudáveis orientadas por cálculos de risco. No campo da saúde, os estudos epidemiológicos se apropriam do conceito de risco com a premissa de diminuir os agravos em saúde.
De acordo com Czeresnia (2004), a identificação e a redução dos riscos se tornaram elemento central da Saúde Pública, que buscou reorientar as estratégias de intervenção na área da saúde visando estender a longevidade humana ao máximo possível. Nesse sentido, os discursos referentes à promoção de um estilo de vida saudável/ ativo se apropriam de "fatores de riscos", ao propagarem o estilo de vida correto. A preocupação atual está em prevenir a ocorrência na população de comportamentos indesejáveis que produzem riscos à saúde. Agora, os indivíduos buscam sistemas de especialistas para o cuidado com o corpo individual. "A vida social é regulada pela confiança em sistemas abstratos que, baseados no conhecimento cientifico, orientam as escolhas através de cálculos de riscos [...]" (CZERESNIA, 2004, p. 447).

No que se refere ao Programa de Educação em Saúde investigado, podemos interpretar como um bom exemplo de conselheiro, em que os especialistas, respaldados pelo conhecimento científico, oferecem orientações para o cuidado com o corpo dos indivíduos. Em nossas análises, encontramos depoimentos dos participantes que evidenciam que a busca dos mesmos pelo programa está associada ao interesse na perda de peso, cujo programa seria uma possibilidade de ajuda para o alcance de seus anseios:

O objetivo é perder peso, eliminar peso. Estou me sentindo mal já, com pressão alta [...] (VÂNIA, trecho do diário de campo, em 14-8-2013.).

Meu objetivo é perder peso. [...] Tenho problema de saúde, problema na coluna, muito bico de papagaio (JACIARA, trecho da entrevista, em 10-10-2013). 
Diante das narrativas, podemos notar que as informações especializadas disponibilizadas pelo programa servem para compor um arsenal privado em prol do emagrecimento. Segundo Bauman (1999), se, por um lado, o conhecimento científico, informado pelos especialistas, é capaz de proporcionar aos indivíduos suporte e técnicas para a diminuição de incertezas e ambivalências para poderem agir no controle de suas próprias vidas, por outro lado, essa emergência de diferentes especialistas e conselheiros pode contribuir para intensificar a responsabilidade dos indivíduos para o cuidado com o corpo, visto que a maioria desses discursos é direcionada para o âmbito privado, colaborando, dessa maneira, no reforço da preocupação do cuidado individual com o corpo e na busca ansiosa pela escolha correta, dentre os inúmeros e distintos conselhos disponibilizados (BAUMAN, 1999). Esse processo, por sua vez, representa a dependência dos indivíduos diante dos especialistas, ao mesmo tempo em que "liberta" os indivíduos para o cuidado individual.

Em relação à legitimidade do conhecimento científico, para a orientação das ações humanas no cuidado com o corpo, Castiel (1999) nos alerta que nem sempre o racionalismo moderno oferece garantias duradouras, visto que os estudos epidemiológicos se baseiam em probabilidades e não em afirmações determinísticas. Isto é, mesmo com um conhecimento provisório, os dilemas enfrentados na busca de um corpo saudável reforçam as exigências em torno daqueles que se encontram fora desse modelo. Apesar de constatarmos, em nossa pesquisa, que a busca dos usuários pelo programa está relacionada à busca pelo emagrecimento, verificamos que essa procura esteve atrelada a "fatores externos à sua vontade", como influência do discurso médico, da pressão social e da aceitação social vinculada a preocupações estéticas. Segundo relatos dos usuários, as consultas médicas eram marcadas por "alertas" dos médicos em relação ao excesso de peso e a apresentação dos agravos em saúde nos diagnósticos realizados:

Eu fiz uma porção de exames. Eu tive com a médica aqui [na U.B.S], com uma porção de exames e conversamos certinho. Ela falou assim: 'para tentar emagrecer de tudo quanto é jeito, o seu peso está bem acima do que é o normal' (WAGNER, entrevista).

Em relação à conduta médica, Gomes (2009) afirma que os discursos médicos parecem ser orientados por uma cartilha em que se seguem à risca as "condutas" consideradas "corretas". Esses discursos generalizantes são balizados, principalmente, por estratégias preventivas. Aos indivíduos que apresentam estilos de vidas considerados de risco, como fumantes, sedentários e com sobrepeso, são direcionados discursos visando à mudança de hábito. Muitas vezes essas falas possuem características de tom culpabilizador, considerando os sujeitos como os únicos e exclusivamente responsáveis por sua condição corporal.

Outras instâncias influenciaram a escolha dos usuários em emagrecer, como o próprio vínculo social que os usuários estão imersos. Encontramos relatos também em que parentes e colegas dos colaboradores adotaram esse discurso de regulação e normatização corporal:

Porque a gente vai chegando numa idade que tem que procurar se cuidar 
mais. E todo mundo falando do peso, que não sei o que, que a alimentação não está saudável, pensei: 'não eu tenho que dar um jeito de mudar! [risos] [...] Eu não posso continuar assim!' As pessoas também influenciaram na escolha [de emagrecer]. [...] O marido influenciou também, por esse lado aí ele influenciou, porque ele é bem chatinho, ele cobra, porque a gente gosta de sair e quando a gente sai, ele fala: 'as mulheres estão tudo magrinha só você que está gordinha' (MARIA APARECIDA, entrevista).

Em relação ao corpo com excesso de peso, podemos perceber a preocupação da usuária com a aparência "gorda" ao ser cobrada pelo seu companheiro para emagrecer. De acordo com Vigarello (2006), o discurso em favor da saúde atrelada à dinamicidade dos corpos possibilitou que a beleza passasse a ser associada à norma do corpo contemporâneo desejado. O bem-estar associado à beleza parece ser a marca atual. Construir a própria aparência é construir e revelar o próprio eu. Contudo, Vigarello nos adverte que todo esse discurso de valorização de si mesmo e de escolhas camufla e potencializa a exigência contemporânea de transformar-se, no qual a coerção social de adequar-se as normas e o controle do corpo se fazem presentes.

Os meios de comunicação de massa, como veículo de propagação da indústria cultural, e o crescimento do mercado consumidor favoreceram essa busca por um corpo saudável cuja aparência corporal se tornou uma preocupação contemporânea. Para Courtine (2005), a busca por um corpo ideal na sociedade de consumo está atrelada à busca pela satisfação pessoal. Os fornecedores de bens de consumo estão ansiosos por seduzir os indivíduos a sustentar a aparência da boa forma. Assim, a busca de um prazer pessoal está vinculada com o desejo de alcançar o padrão estético ideal. No caso, os produtos "milagrosos" estéticos seriam a chave do alcance dessa felicidade, e os exercícios físicos os aliados da boa forma. Não é de estranhar que a preocupação com o corpo na atualidade se tornou um dos temas centrais em nossa vida. Existe uma busca incessante por um corpo belo, sarado e jovem cuja estética esbelta se transforma no escopo das ações e anseios humanos. O culto ao corpo é entendido como uma relação em que os indivíduos possuem como preocupação elementar a modelação dos seus corpos, seja por meio de atividades físicas, uso de produtos cosméticos, dietas, cirurgias plásticas, seja por meio de outros artifícios. Todos esses "aparatos" para a modelagem estética do corpo são fundamentais para a aproximação da aparência corporal ao padrão de beleza estabelecido. "Faça algo por você" constitui um dos principais imperativos da sociedade atual. Cuidar da aparência tornou-se um item necessário de aceitação social (CASTRO, 2003).

Essa preocupação com esse modelo corporal aparece no trecho a seguir: "Eu acho que os outros gostariam que a gente fosse sempre magra! Poderia ser mais magra um pouquinho, sempre!" (MARINALVA, trecho do diário de campo em 11 set.). A tentativa de adequação a tal imperativo revela, necessariamente, a negação daquilo que escapa a esse ideal. Assim, o corpo gordo é visto como um simulacro provisório, uma travessia a ser passada e abandonada. Segundo Góis (2009), a procura dos indivíduos com excesso de peso por um corpo magro revela, sobretudo, a procura de si, de sua identidade na sociedade contemporânea. 
Os discursos sociais culpabilizantes e de responsabilização direcionados aos indivíduos que não se enquadram ao modelo corporal em voga contribuem para o cenário presente dessa forma de exclusão social. No imaginário social, a figura do obeso é estigmatizada e atrelada à feiura e ao desleixo, o que contribui para a emergência do preconceito social. Com tais características, o obeso passa a ser alvo de críticas e chacotas, contribuindo para o engendramento de inúmeros problemas psicossociais. Sabemos que a obesidade pode colaborar com o agravo de doenças, mas entendemos que, além desse agravante, o obeso carrega a preocupação com a aceitação social. A seguir, um relato que evidencia claramente isso:

Eu acho que as pessoas me veem gorda e fala ainda por cima! [risos]. Eu, assim, eu fiquei magoada, chateada, porque todo mundo sabe que é gorda, mas não gosta de ser chamada de gorda! $\mathrm{E}$, assim, eu não sou gorda; eu tenho excesso de fofura! A pessoa falou assim: 'Poxa, você está se preparando porque o mundo vai acabar em água de novo, porque as boias já estão do lado!' [risos]. Sempre esses comentários: 'Você está achando que o mundo vai acabar em água de novo, igualzinho a Noé, você já tá com as boias do lado'. Então, a cada crítica que você recebe, é como as pessoas te veem, né?. 'Essa roupa tá parecendo uma capa de botija em você!'. Eu me sentia uma botija!. Sabe quando você pensa assim: 'Poxa vida, será que eu estou tão feia assim?' Aí você vai lá e a roupa nem está feia, vai lá e troca, porque a crítica foi tão grande, entendeu? São várias piadinhas que tem de gordo, que a gente fica assim!Eu já entrei em depressão! (SILVANA, trecho do diário de campo, em 11-9-2013).
Bourdieu (2007) nos ajuda a entender esse cenário ao afirmar que a relação com o corpo é permeada pela representação da imagem que se tem do próprio corpo e, principalmente, pelo feedback construído advindo dos olhares de outras pessoas que avaliam e julgam esse corpo. Dessa forma, a construção da representação da nossa imagem corporal sofre interferência interna, referente àquilo que nos parece ser, e externa, alusiva àquilo que é visto por meio da nossa interação com o mundo.

Cultivar a beleza, a boa forma e a saúde aponta para uma nova ideologia que se impõe com um estilo ideal de viver bem. A gordura aparece como um refugo que deve ser eliminado, contribuindo com a sua negatividade e para a emergência de uma sociedade lipofóbica. Assim, muito mais que o peso corporal, o obeso sustenta o peso social, pois carrega significados negativos presentes na sociedade (NOVAES, 2006).

Como foi possível interpretar neste tópico, na atualidade, há uma busca infindável na procura por orientações especializadas nas quais o corpo se tornou o lócus de intervenções. Essa aura de incerteza e insegurança em relação ao futuro, que assola o imaginário dos indivíduos contemporâneos, decorre justamente do fato de que ao indivíduo é direcionada à responsabilidade de gerenciar a sua vida. As preocupações relatadas pelos participantes referentes ao cuidado com o corpo reforçam a tese baumaniana sobre a privatização da vida em que os indivíduos são responsabilizados pelos seus infortúnios individuais.

A busca dos usuários pelo programa esteve atrelada à busca por segurança, almejando, dessa forma, o afastamento de dúvidas e incertezas em relação ao cuidado 
com o corpo. O interesse por informações e estratégias de como agir de maneira "correta", seja em relação à alimentação, seja à prática de atividade física, foi revelado pelos participantes com o objetivo de diminuir as incertezas referentes ao trato com o próprio corpo. Entendemos, também, que a exigência de se adequar às normas produz uma sociedade prisioneira na incansável busca pela satisfação corporal. De acordo com Bauman (2001), o corpo contemporâneo é o último reduto de segurança. Nesse sentido, parece-nos que a busca por segurança não é garantia da eliminação absoluta de nossas angústias e sofrimentos, mas geradora de mais incertezas. Por último, se, por um lado, ganhamos mais opções para o cuidado corporal, por outro seguimos reféns do modelo de vida correto em que o corpo magro e o estilo de vida saudável/ativo são alvos de admiração e desejo.

\section{Entre ações e discursos: a recepção dos usuários em frente aos discursos dos espe- cialistas do Programa}

O emagrecimento e a mudança de hábito de vida, voltados para a adesão de um estilo saudável, que estavam no escopo das preocupações dos usuários investigados, bem como arrolados no propósito do programa, convergiram ao se materializar no cotidiano produzido pelos usuários e especialistas. Isto é, os participantes esperavam encontrar informações para mudar seus hábitos de vida na busca pelo emagrecimento e visualizaram no programa ferramentas para a "diminuição" de suas angústias referentes aos cuidados corporais.

Ao acompanharmos o cotidiano dos encontros do programa, foi possível observar que os usuários apresentaram comportamento de assentimento e aprovação ao receber as informações dos especialistas e procuravam utilizá-las no seu dia-a-dia:

Hoje eu fiz o que você mandou: fiz uma saladinha, ontem a noite para comer hoje de manhã! (NILDA, trecho do diário de campo em 02 out.).

[...] Então, assim, a orientação do grupo foi boa, por quê? Porque tudo que eu vou comer hoje, tudo que eu vou fazer, eu penso duas vezes antes de fazer e se eu como alguma coisa além, eu compenso no outro dia com outra coisa [...]. A orientação foi ótima, sempre eu penso: 'se eu posso comer um chocolate, por que eu vou comer a barra toda?' Um pedacinho já me satisfaz! (SILVA$N A$, entrevista).

O comportamento comedido, baseado em uma escolha racional orientada pelos especialistas, pode ser verificado nessas narrativas. Assim, observamos a presença de elementos que remetiam a prática de caminhadas e alongamentos e o uso de saladas e frutas como formas de cuidado com o corpo no cotidiano desses sujeitos; elementos também identificados e construídos nos mapas corporais.

Contudo, identificamos que, além do conhecimento científico, outros elementos, como por exemplo, "o estar com [o outro]", por meio da produção de vínculos afetivos, também foram ressaltados pelos usuários no que se refere aos cuidados com o corpo. Em alusão a essa afirmação, no último encontro de cada módulo, para celebrar o fechamento das atividades, observamos que os especialistas do programa organizam, juntamente com os usuários, uma confraternização. Identificamos que 
a camaradagem entre os participantes favoreceu a formação de laços de amizade entre usuários e especialistas, bem como o surgimento de relações de reconhecimento entre os frequentadores ao se identificarem com os sofrimentos e anseios experimentados pelos colegas do grupo:

Há maravilhoso, foi ótimo, porque a cada encontro a gente conheceu pessoas novas, fez amizades novas e é bom que no dia-a-dia, pude ver que tem pessoas, as vezes, piores que a gente. A gente está sentindo, assim, o pior de tudo e todos nós somos iguais, então, todos nós estamos ali uma ajudando a outra...muito legal! Me senti muito a vontade, geralmente, assim, quando eu estou em grupo não sou muito de falar e lá eu tava bem falante, então, assim, me senti a vontade, me senti como se estivesse no meio de pessoas conhecidas já que eu conhecia a muito tempo (SILVANA, entrevista).

Esse compartilhamento no grupo nos pareceu um fator adicional para que os usuários persistissem no programa com o intuito de alcançar a diminuição do peso corporal. O incentivo em motivar uns aos outros (papel esse também desempenhado pelos especialistas) e a constante troca de dicas, foram estratégias que proporcionaram a permanência dos participantes em relação aos seus objetivos em função de que os próprios integrantes serviam de referência uns aos outros na tentativa de superação das angústias e dilemas enfrentados individualmente fora do programa. Quer dizer, em frente a dificuldades similares, evidentes para aqueles que experimentam as mesmas dificuldades, é que os indivíduos se identificam na expectativa de vencê-los (BAUMAN, 2001). Tal aspecto se assemelha ao que Rabinow (1999) chamou de biossociabilidade, em que uma organização social se fundamenta em princípios atrelados ao cuidado com a saúde, performance corporal, doenças, dentre outros.

Segundo relatos dos frequentadores do grupo, a necessidade de alterar seus comportamentos não exigiu muitos esforços, o que demonstraria o consentimento das pessoas em face às informações acessadas por meio do programa: "Não, foi difícil não, porque comer eu já comia pouco e na medida certa, já comia. Porém comia errado, não comia nos horários certos, então, o negócio foi se adaptar aos horários, então para mim não foi difícil não" (SILVANA, entrevista).

Identificamos que os participantes não compreenderam a alteração de suas práticas como resultado de sacrifícios assumidos. ${ }^{1}$ Podemos concluir que os membros anuíram as dicas recebidas, conferindo um dimensão positiva aos cuidados corporais. Conforme os depoimentos, mal-estares de caráter biológico, como hipertensão, dores nas costas e falta de ar, foram minimizados graças à diminuição de peso. Vantagens vinculadas à estética corporal, como o uso de roupas que antes não cabiam e a exaltação do se sentir bonita ao emagrecer, corroboram nosso argumento segundo o qual a apreensão com a gordura corporal, no mundo atual, vai além da preocupação com a saúde e se atrela, fortemente, à dimensão estética. Identificamos aqui as bioasceses descritas por Ortega (2003):

12 Contudo, vale ressaltar que não acompanhamos os usuários após o término dos encontros. Assim, somente uma pesquisa com um acompanhamento mais ampliado poderia verificar se essas informações se materializaram como hábito no cotidiano desses sujeitos. 
Somente sendo idênticos à norma é que podemos nos esconder. A adaptação, a obediência e a identificação com a norma é o refúgio do eu que fez de sua aparência a essência. Queremos ser iguais para nos protegermos, nos escondermos. Ou somos idênticos, ou nos denunciamos (ORTEGA, 2003, p.70).

No que diz respeito a postura contida dos participantes diante dos esclarecimentos recebidos, e mesmo que afirmem seguir as recomendações sem sacrifícios, alguns limites a serem ultrapassados foram nomeados. As circunstâncias de vida integram as escusas arroladas para se entender a adesão ou não dos envolvidos em hábitos de vida saudáveis, bem como colocar em dúvida o argumento que culpabiliza os indivíduos por seus comportamentos de risco e/ou desviantes, em que eles são os únicos responsáveis pela sua condição corporal. Lamentos relacionados à inexistência de tempo para a adoção de tais estilos e as limitações financeiras para gasto com determinados produtos tidos como saudáveis foram mencionadas pelos participantes durante os encontros, deixando claro que as circunstâncias que envolvem o cuidado de si corporal vão além dos limites de ordem pessoal, envolvendo, também, questões de ordem econômica e sociocultural.

Em relação às dificuldades apresentadas, percebemos que estavam relacionadas também com o prazer de comer. Os obstáculos referentes aos prazeres que a comida proporciona puderam ser evidenciados também na produção dos mapas corporais. Figuras associadas a bolos, doces e pizzas eram selecionadas pelos usuários que elucidavam a dificuldade de resistir a tais alimentos. Outros relatos evidenciam essa circunstância: “O meu ponto fraco é a lanchonete lá perto de casa [risos]. É o gostar de comer. O negócio é fugir dos doces, das guloseimas... É difícil [...]" (SILVANA, trecho do diário de campo, em 02-10-2013).

Dessa forma, mesmo diante da conformidade das ações ao considerar práticas que são vistas como "corretas" para o viver bem (o excesso das ações precisa ser controlado para se obter um corpo saudável), lidar com o controle de desejos e volições parece ser um tanto quanto difícil. Se, por um lado, o alimento é fonte de prazer, por outro se configura como fonte de sofrimento, visto que o excesso de consumo pode ser o fator contribuinte pela manutenção da sua condição de gordo. De acordo com Bauman e May (2010), o corpo é um local de ansiedade e também de prazer. Ações como comer e beber fazem parte de eventos sociais que são capazes de proporcionar experiências prazerosas. Ao reduzirmos essa capacidade de sensação, estamos da mesma forma diminuindo as interações que elas promovem.

Em relação à busca pelo emagrecimento, o grupo investigado também apresentou representações diferentes em relação ao cuidado com o corpo obeso. Enquanto alguns participantes almejavam emagrecer até chegar ao corpo ideal (magro), outros não possuíam no escopo de preocupação a mesma intensidade desse objetivo:

Pretendo melhorar cada vez mais, emagrecer cada vez mais e chegar ao meu peso certo, na medida certa (MARIA APARECIDA, trecho da entrevista, em 10-10-2013).

[...] eu não quero chegar ao peso da minha altura, não. A médica falou que, para minha altura, seria cinquenta e cinco, mas também não quero, sempre fui, 
assim, gordinha (JACIARA, trecho da entrevista, em 10-10-2013).

Diante do apresentado, podemos notar que nem todos os participantes são meros indivíduos que absorvem as informações passivamente em relação ao cuidado com o corpo. A ponderação com referência ao emagrecimento e ao uso dessas informações no cotidiano demonstra que a usuária se assume como protagonista da sua ação, decidindo sobre a escolha que melhor convém à sua realidade.

Uma saúde aberta ao risco (CAPONI, 2003) contribui para pensarmos em linhas de fuga frente aos imperativos vinculados ao estilo de vida saudável, como por exemplo, ao mencionarmos o exemplo da frequentadora que admite não alcançar o "peso ideal", mesmo diante das prescrições apresentadas. Essa possibilidade de "não" frente a essa regulamentação nos coloca diante de outros caminhos possíveis nas práticas educativas em saúde.

Pelo exposto, entendemos que o corpo, sobretudo o obeso, na sociedade de risco, não é livre para experimentar suas vontades e quereres, já que preferências são direcionadas com o propósito de orientar posturas na direção de um estilo de vida saudável. Todavia, Carvalho e Martins (2004) afirmam ser factível obter maior liberdade das escolhas uma vez que as pessoas descubram suas "verdadeiras" necessidades e, assim, passem a realizá-las e querê-las. Quer dizer, a vontade de fazer seria uma iniciativa capaz de elevar a nossa potência de agir. Entendemos que o estabelecimento de sentimentos de afetos, produzidos no dia a dia das práticas em saúde graças aos encontros realizados, pode ser um expediente potente empregado pelos especialistas, na esperança de estimular os usuários a descobrirem seus "reais" interesses, desejos e propósitos ao se ocuparem de seus corpos. Assim sendo, vislumbramos a elaboração de laços afetivos como promoção de saúde na medida em que vislumbramos a produção de vínculos como a capacidade para a expansão da potência de vida e a intensificação da existência.

\section{CONCLUSÃO}

Procuramos evidenciar que a preocupação em emagrecer esteve atrelada, em um primeiro momento, à preocupação dos usuários com os agravos à saúde. Contudo, a pressão social representada pelo saber médico, os laços sociais dos participantes (familiares e pessoas próximas), bem como a interferência da estética como valor moral de aceitação social também foram elementos apresentados e que contribuíram para que os participantes buscassem a perda de peso. O abandono desse corpo gordo, carregado de peso moral e físico, representaria a reconstrução desses indivíduos para o convívio social.

Dessa forma, temos a premissa de que sofremos em nossos corpos a pressão da coerção social. Isso reflete a constante preocupação que temos diante do cuidado do corpo. O corpo se torna algo a ser moldado, construído, baseado no padrão corporal propagado socialmente e essa exigência corporal acaba excluindo aqueles que não se assemelham a ela. A rejeição da gordura se manifesta na preocupação em apresentar uma aparência bela, ao consideramos o corpo magro (sarado) como modelo ideal de beleza. A sociedade contemporânea, portanto, impõe aos indivíduos uma pressão 
cultural para emagrecer. Em decorrência dessa cobrança externa e do temor à gordura, é que usuários escolheram o programa como uma forma de conselheiro seguro para a orientação de suas ações e escolhas na busca pelo emagrecimento e pela diminuição das angústias modernas vinculadas à gordura.

Em relação à adesão dos usuários às informações recebidas, os indivíduos apresentaram comportamentos de conformidade ao absorverem e transportarem as condutas orientadas pelos especialistas para o seu cotidiano. Acreditamos que essa conduta esteja relacionada com a busca não só de alívios associados a dores no corpo, hipertensão e diabetes, mas também à própria busca dos participantes em serem aceitos socialmente. Portanto, ao considerarmos que o modelo correto de viver bem, em uma sociedade contemporânea, é atrelado ao estilo de vida saudável, por mais que os participantes com excesso de peso apresentem dificuldades em aderir a esse estilo, a "naturalização" desses ideais acaba por contribuir na formação de conformidades de hábitos, ao acreditarem que esta seria a única forma correta de vida.

A cristalização desses enunciados na sociedade contemporânea são incorporados e reconhecidos no mundo social. No entanto, tencionar tais discursos regulamentadores nas práticas de educação em saúde se apresentam como uma via de ação factível. Diante dessas ponderações, apostamos que a criação de vínculos afetivos se apresenta como uma força motriz em condições de alimentar novos arranjos frente às prescrições biomédicas sobre o corpo, bem como uma válvula de escape das incumbências das políticas públicas de saúde em propagar modos e práticas normativos sobre o corpo e a vida dos indivíduos. Segundo Gastaldo (1996, p.116), “[...] a política social não é uma única fonte de poder, vertical, do nível federal até o local. O processo de promoção do saber e de criação de normas ocorre dentro de uma rede de micropoderes, onde muitas formas de controle e resistência são articuladas [...]". Assim, mesmo diante do poder emanado por instâncias superiores, acreditamos que as relações sociais materializadas no cotidiano em que as práticas de saúde são produzidas e articuladas entre os diferentes sujeitos do processo de produção do saber (especialistas, funcionários e comunidade) se tornam um território propício para a formação e [re]configuração de modos de vidas em frente às ações e normas "duras", "generalizantes", "biologizantes" e "ideológicas" emergidas do contexto social.

Acreditamos que a formação dessa rede de encontro é importante à medida que torna mais potente a criação de um ambiente favorável para a reivindicação de políticas efetivas, bem como se constituem em momentos mais propícios para a elaboração de discursos que não se restrinjam à prescrição dos cuidados corporais. É evidente que encontrar modos conscientes e criativos de se produzir saúde talvez seja o grande desafio a ser superado. Considerar e incitar a produção dos laços afetivos entre os sujeitos pode contribuir para uma maior qualidade das relações desses indivíduos. Uma atenção ao risco, além do que se entende de controle, seria, também, pensar em produzir saúde (CAPONI, 2003). Nesse sentido, compreendemos ser fundamental o estudo sobre essas temáticas que perpassam em nosso cotidiano, pois é a partir dessas reflexões que podemos entender as amarras produzidas e criar possíveis válvulas de escape como dispositivos de reação a esses controles sociais. 


\section{REFERÊNCIAS}

BAGRICHEVSKY, M. et al. Sedentário "semvergonha", saudável "responsável"? Problematizando a difusão do "estilo de vida ativo" no campo sanitário. In: BAGRICHEVSKY, M.; PALMA, A.; ESTEVÃO, A. (Org.). A saúde em debate na educação física. Ilhéus: Editus, 2007. v. 3, p. 209-230.

BAUMAN, Z. Modernidade e ambivalência. Rio de Janeiro: Jorge Zahar Ed.,1999.

- Modernidade líquida. Rio de Janeiro: Jorge Zahar Ed., 2001.

BAUMAN, Z.; MAY, T. Aprendendo a pensar com a sociologia. Rio de Janeiro: Zahar, 2010.

BOURDIEU, P. A distinção: crítica social do julgamento. São Paulo: Edusp; Porto Alegre: Zouk, 2007.

CAPONI, S. A saúde como abertura ao risco. In: CZERESNIA D., FREITAS C. M. (Org.). Promoção da saúde: conceitos, reflexões, tendências. Rio de Janeiro: Fiocruz, 2003. p. 55-77.

CARVALHO, M. C.; MARTINS, A. A obesidade como objeto complexo: uma abordagem filosófico-conceitual. Ciência \& Saúde Coletiva, Rio de Janeiro, v. 9, n. 4, p.1003-1012, 2004.

CASTIEL, L. A medida do possível... saúde, risco e tecnobiociências. Rio de Janeiro: Contra Capa Livraria; Rio de Janeiro: Editora Fiocruz, 1999. p. 204. ISBN 85-85676-70-1. Available from SciELO Books. Disponível em: < http://books. scielo.org >. Acesso em: 02 jan. 2014.

CASTIEL, L. D.; DIAZ, C. A. D. A saúde persecutória: os limites da responsabilidade. Rio de Janeiro: Editora Fiocruz, 2007. p.136.

CASTIEL, L. D.; GUILAM, M. C. R.; FERREIRA, M. S. Correndo o risco: uma introdução aos riscos em saúde. Rio de Janeiro: Editora Fiocruz, 2010.

CZERESNIA, D. Ciência, técnica e cultura: relações entre risco e práticas de saúde. Cad. Saúde Pública, Rio de Janeiro, v. 20, n. 2, p. 447-455, mar./abr.2004.

COHEN, R; CUNHA, M. R. A obesidade. São Paulo: Publifolha, 2004.

FRAGA, A. B. Exercício da informação: governo dos corpos no mercado da vida ativa. Campinas: Autores Associados, 2006.

GASTALDO D. Is health education good for you? The social construction of health education in the Brazilian national health system. 1996. Tese University of London, London, 1996.

GASTALDO, D. et al. Body map storytelling as research: Methodological considerations for telling the stories of undocumented workers through body mapping. 2012. Disponível em: $<$ http://www. migrationhealth.ca/ undocumented-workers-ontario/bodymapping >. Acesso em: 5 fev. 2014.

GASTALDO, D.; MAGALHÃES, L.; CARRASCO, C. Mapas corporais narrados: um método para documentar trajetórias de saúde, resiliência, adoecimento e sofrimento. In: FRAGA, A. B.; CARVALHO, Y. M.; GOMES, I. M. (Org.). As práticas corporais no campo da saúde. São Paulo: Hucitec, 2013. p. 52-52.

GOELLNER, S. V. Bela, maternal e feminina: imagens da mulher na Revista de Educação Physica. Ijuí-RS: EdUnijuí, 2003.

GÓIS, C. E. A procura de si: a representação do corpo gordo em Cíntia Moscovich. Estudos de Literatura Brasileira Contemporânea, Brasília, n. 33, p. 5970, jan./jun. 2009. 
GOMES, I. M. Conselheiros modernos: propostas para a educação do indivíduo saudável. Brasília: Thesaurus/CBCE, 2009.

MACEDO, R. S. A etnopesquisa crítica e multirreferêncial nas ciências humanas e na educação. Salvador: Edufba, 2000. MOROSINI, M. V.; FONSECA, A. F.; PEREIRA, I. B. Educação em saúde. In: Dicionário da educação profissional em saúde. Rio de Janeiro: Fundação Oswaldo Cruz, 2009. Disponível em: < http://www.epsjv.fiocruz.br/dicionario/ verbetes/edusau.html $>$. Acesso em: 15 fev. 2014.

MOSER et. al. Pressão arterial elevada, excesso de peso e obesidade abdominal em crianças e adolescentes. R. da Educação Física/UEM, Maringá, v. 22, n. 4, p. 591-600, 4. trim. 2011.

NOVAES, J. V. O intolerável peso da feiúra: sobre mulheres e seus corpos. Rio de Janeiro: Garamond/Ed. PUC. 2006.

ORTEGA, F. Práticas de ascese corporal e constituiçäo de bioidentidades: practices of corporal ascetics and the building of bio-identities. Cad. Saúde Colet., Rio de Janeiro, v. 11, n. 1, p. 5977, jan./jun. 2003.

PETRIBÚ, K. Comorbidade no transtorno obsessivo-compulsivo. Rev. Bras. Psiquiatr, Rio de Janeiro, v. 23, suppl.2, p.17-20, out. 2001.

PIMONT, R. P. A educação em saúde: conceitos, definições e objetivos. Boletin de la Oficina Sanitaria Panamericana, p. 14-22, enero 1977.

POLI NETO, P.; CAPONI, S. N. C. The "medicalization" of beauty. Interface Comunic., Saúde, Educ., v. 11, n. 23, p. 569-84, set./dez. 2007.

RABINOW, P. Antropologia da razão. Rio de Janeiro: Relume Dumará, 1999.

RAMIRO, A. Estratégias de governamentalidade no âmbito da promoção da saúde: o controle do peso corporal como estilo de vida saudável. São Paulo: Pontifícia Universidade Católica de São Paulo, 2008.

\section{AN INTERPRETATION OF BODY CARE BY USERS OF A PUBLIC HEALTH SYSTEM PROGRAM IN VITÓRIA/ES}

\section{ABSTRACT}

This paper addresses topics on Health Education and risk behavior. Research was carried out to investigate how users deal with information received from a Health Education program, in Vitória (Espírito Santo, Brazil), focused on intervention in overweight and obese individuals. The methodological tools used were participant observation, semistructured interviews and experimentation with the technique of Body-Map Storytelling. We conclude that the individuals showed evidence of conformity by absorbing and conveying the behavior recommended by experts to their daily lives. We believe that this finding is linked to the fact that, in contemporary society, the model of living well corresponds to healthy lifestyle, in which the "naturalization" of these ideals ultimately contributes to the acceptance of these norms due to the belief that this would be the only right way of living.

Keywords: Obesity; Health Education; Healthy lifestyle 


\section{UNA INTERPRETACIÓN DE LOS CUIDADOS CORPORALES A PARTIR DE LOS USU- ÁRIOS DE UN PROGRAMA DE LA RED PÚBLICA DE SALUD EN LA CIUDAD DE VITÓRIA/ES}

\section{RESUMEN}

Este artículo trata de las temáticas relacionadas a la Educación en salud y el comportamiento de riesgo. Tuve como objetivo investigar cómo los usuarios tratan las informaciones que reciben de un programa de Educación en salud, ofrecido en las unidades básicas de salud en la ciudad de Vitória en la provincia de Espírito-Santo/Brasil, enfocado en la intervención de individuos con sobrepeso y obesidad. Los instrumentos metodológicos utilizados fueron observación participante, entrevistas semiestructuradas y la experimentación de la técnica Narrativas de Mapas Corporales. Después de los análisis, se concluye que los individuos presentan comportamientos de conformidad al observar y transportar las conductas orientadas por los especialistas para su cotidiano. Esta constatación puede estar presa al hecho de que, en la sociedad contemporánea, el modelo de vivir bien es el estilo de vida saludable, en que la "naturalización" de estos ideales contribuye en la aceptación de estas normas al creer que esa sería la única forma correcta de la vida.

Palabras clave: Obesidad; Educación en Salud; Estilo de Vida Saludable

Recebido em: junho/2015

Aprovado em: dezembro/2015 